\title{
Methamphetamine Use, Attitudes About Condoms, and Sexual Risk Behavior Among HIV-Positive Men Who Have Sex with Men
}

\author{
Nadine Nakamura $\cdot$ Brent T. Mausbach • \\ Monica D. Ulibarri · Shirley J. Semple • \\ Thomas L. Patterson
}

Received: 11 March 2009/Revised: 21 August 2009/ Accepted: 19 September 2009/Published online: 24 October 2009

(C) The Author(s) 2009. This article is published with open access at Springerlink.com

\begin{abstract}
This study examined attitudes about condoms as a moderator of the relationship between methamphetamine use and sexual risk behavior in a sample of 297 HIV-positive, methamphetamine-using men who have sex with men (MSM). To test for a moderating effect of attitudes towards condoms, an interaction term was included in multiple regression analysis along with age, income, negative condom attitudes, frequency of methamphetamine use, and Beck depression score. A post hoc analysis was conducted to determine the relations between methamphetamine use and unprotected sex for persons with more vs. less negative attitudes toward condoms. These analyses indicated that when individuals had more negative attitudes toward condoms, the relation between methamphetamine frequency and unprotected sex was significant, while among participants with less negative attitudes toward condoms, no significant association was found. Addressing methamphetamine-using MSM's attitudes about condoms can serve as a form of harm reduction for those who are not yet ready or willing to discontinue methamphetamine use.
\end{abstract}

Keywords Methamphetamine - Attitudes · Condoms . Sexual risk $\cdot$ Men who have sex with men

N. Nakamura · B. T. Mausbach · M. D. Ulibarri ·

S. J. Semple · T. L. Patterson $(\square)$

Department of Psychiatry (0680), University of California, San Diego, 9500 Gilman Drive, La Jolla, CA 92093-0680, USA

e-mail: tpatterson@ucsd.edu

T. L. Patterson

MIRECC, San Diego VA Medical Center, La Jolla, CA, USA

\section{Introduction}

According to the Centers for Disease Control and Prevention (2007), more than half a million men who have sex with men (MSM) have received an AIDS diagnosis in the United States. While only 5-7\% of men in the United States reported having had sex with other men, MSM made up more than two-thirds (71\%) of all men living with HIV in 2005. In 2005, the number of new HIV/AIDS cases among MSM was $11 \%$ more than the number of new cases in 2001. While it is not clear whether this increase is due to increased HIV testing or to higher rates of infection, what is certain is that HIV continues to be a serious health threat to MSM.

The rise of HIV among MSM may correspond with the rise in methamphetamine use in this population (CDC, 2007). Methamphetamine use has been identified in a number of studies as a predictor of risky sexual behavior among MSM (Colfax \& Shoptaw, 2005; Halkitis, Parsons, \& Stirratt, 2001; Semple, Patterson, \& Grant, 2002). Methamphetamine users often report decreased sexual inhibition, increased self-esteem, euphoria, and hypersexuality when under the influence (Halkitis et al., 2001). Methamphetamine use has also been associated with a number of sexual risk factors, including enhanced sexual drive, behavioral disinhibition, increased desire for high risk activities, low rates of condom use, high rates of sexually transmitted disease, and multiple partners (Colfax \& Shoptaw, 2005). Methamphetamine not only increases HIV-negative users' risk, but it also has serious health consequences for HIV-positive users by increasing neuropsychological deficits and decreasing medication adherence (Colfax \& Shoptaw, 2005).

Not everyone who uses methamphetamine has unprotected sex (Crosby, Stall, Paul, \& Barrett, 1996). Recent studies have challenged the ideas that methamphetamine use necessarily leads to increased risky sexual behavior and that it therefore should be the primary focus of our HIV-prevention efforts 
(Grov, Parsons, \& Bimbi, 2008; Rawstorne, Digiusto, Worth, \& Zablotska, 2007). Rawstorne et al. (2007) examined data from two cohort studies of Australian MSM and found that, while there was an increase in methamphetamine use from $26 \%$ in 2002 to $39 \%$ in 2005 , the rate of unprotected anal sex with casual partners either did not change or actually decreased during this time. Rawstorne et al. concluded that since there is no evidence that the proportion of unsafe sex is directly caused by methamphetamine use, other variables that are correlated with both methamphetamine use and unsafe sex should be further explored. Thus, it is important to identify for whom and under what circumstances methamphetamine use is associated with risky sexual behaviors. Identifying these factors could provide intervention targets that may aid in reducing the spread of HIV and other sexually transmitted infections.

Attitudes and beliefs about condom use and social norms appear to significantly influence whether substance-using MSM use condoms (Crosby et al., 1996). For example, positive attitudes towards condoms can actually protect against risky sexual behavior (Benotsch, Kalichman, \& Cage, 2002). However, attitudes about condoms have not been examined as a moderator in previous research with methamphetamine-using MSM.

An earlier study of methamphetamine-using, HIV-positive MSM revealed that participants had high rates of depression, and that the majority was using methamphetamine to self-medicate (Semple et al., 2002). Since depression may affect the relationship between condom attitudes and sexual risk behavior, we controlled for depression in our analyses.

In the present study, we examined attitudes about condoms as a factor that may modify the relationship between level of methamphetamine use and sexual risk behavior in a sample of HIV-positive MSM. Specifically, we hypothesized that the relationship between methamphetamine use and sexual risk behavior would be stronger among individuals with attitudes towards condoms that were more negative.

\section{Method}

\section{Participants}

These analyses used baseline data from a sample of 297 men who were enrolled in an eight-session, theory-based, one-onone behavioral intervention designed to reduce sexual risk behaviors of HIV-positive, methamphetamine-using MSM. Eligible participants were HIV-positive MSM who were at least 18 years old and who reported using methamphetamine at least twice in the past two months. Because the study's aim was to reduce sexual risk behaviors, participants also had to report having had unprotected anal or oral sex with at least one HIV-negative or serostatus-unknown male partner during the same period, whereas men who used condoms 100 percent of the time with all HIV-negative or serostatus-unknown partners or who had only HIV-positive partners over the previous two months were excluded. In addition, those who endorsed active suicidal or psychotic symptoms, or who had been HIV-positive for less than two months were also excluded. Findings on the efficacy of the intervention have been published (Mausbach, Semple, Strathdee, Zians, \& Patterson, 2007).

Participants were recruited into the intervention study in San Diego, California through multiple strategies, including largescale poster and media campaigns, street outreach in social environments that were known to have high concentrations of methamphetamine users and MSM (e.g., gay clubs), and referrals from social service providers (e.g., HIV health clinics) or from men already enrolled in the study. The study was advertised as a university-sponsored program for HIV-positive methamphetamine users who wanted to learn more about safer sex practices.

\section{Procedure}

Participants underwent a 60-min, face-to-face, paper-and-pencil baseline interview that covered a range of topics, including background characteristics, depressive symptoms, use of methamphetamine, condom attitudes, and sexual risk practices. Participants were paid $\$ 30$ for completing their baseline assessment and the first session of the counseling intervention. Data for the present analyses were collected between November 2000 and October 2004.

\section{Measures}

\section{Background Characteristics}

Each participant was asked about his age, ethnicity, education, sexual orientation, employment status, and income.

\section{Depressive Symptoms}

Depressed mood was assessed using the Beck Depression Inventory (BDI), which consists of 21 items, each having four graded statements about how the subject has been feeling during the past week (Beck, 1967, 1976). The statements within each question are ordered (0-3) to show increasing depressive symptoms. Summary scores are calculated (range, 0-63).

\section{Frequency of Methamphetamine Use}

This was measured by self-report of the number of days on which methamphetamine was used during the past 30 days.

\section{Negative Condom Attitudes}

Participants' negative attitudes on this topic were calculated by summing responses to the following questions: (1) "I believe that using condoms interferes with sexual pleasure," (2) 
"I believe that stopping to put on a condom ruins the moment," (3) "I believe that using condoms makes me less sexually desirable," (4) "Using condoms during sex ruins the mood," (5) "Using a condom will feel unnatural," and (6) "My partner(s) will not be sexually satisfied if we use a condom" (Mausbach, Semple, Strathdee, \& Patterson, 2009). Responses to items on this scale ranged from $1=$ "Strongly Disagree" to 4 = "Strongly Agree." A high score indicated more negative attitudes about condom use, while a low score indicated less negative attitudes about condom use. Alpha reliability for this scale with our sample was .85 .

\section{Sexual Risk Behavior}

Sexual risk behavior was defined as unprotected anal sex with an opposite- or same-sex partner. Three categories of partner type were assessed: steady (e.g., spouse, boyfriend); casual (e.g., one-night stand); and anonymous (e.g., someone in the park). For each partner type, participants were asked how many times during the past two months they had engaged in receptive anal sex and insertive anal sex. For each type of sex act, participants were asked how many of those times they had used a condom. A summary variable was created to represent total number of unprotected anal sex acts during the previous two months.

\section{Data Analysis}

To determine the moderating effect of negative condom attitudes on the relations between methamphetamine frequency and unprotected sex, a multiple linear regression approach was used (Baron \& Kenny, 1986). Prior to the analyses, all independent variables were centered at their means, as is recommended in the literature (Kraemer \& Blasey, 2004). The following variables were entered as possible predictors of unprotected sex: age, income, BDI score, methamphetamine frequency, negative condom attitudes, and the interaction between methamphetamine frequency and negative condom attitudes (see Table 1).

Post hoc analyses were conducted to determine the nature of the interaction. In these tests, we created a variable for high condom attitudes (i.e., centered negative condom attitudes minus $1 S D$ ) and one for low condom attitudes (i.e., centered negative condom attitudes plus $1 S D$ ). Each of these variables was then multiplied by the (centered) methamphetamine frequency variable to create an interaction term. We then conducted two additional regression analyses, each of which included the main effect for methamphetamine frequency, one of the condom attitude variables (i.e., high condom attitudes or low condom attitudes), and the interaction of the methamphetamine frequency and condom attitudes variable, thereby producing the slope for the high and low condom attitude conditions. Greater details on how to conduct such post hoc analyses as these can be found in Holmbeck (2002).

\section{Results}

\section{Sample Description}

This study used data from 297 participants who had completed baseline assessment in the intervention study. Participants ranged in age from 20 to 61 years, with a mean of 36.89 $(S D=7.27)$. All participants reported having sex with a male partner in the previous two months and were thus categorized as MSM, with the majority (79.1\%) identifying as homosexual or gay, $20.1 \%$ identifying as bisexual, and less than $1 \%$ as "not sure." The majority of participants was White $(56.6 \%)$, followed by African American (21.5\%), Latino (13.1\%), Native American (4\%), Other (4\%), and Asian (.7\%). Most participants had some college education or more $(59.9 \%)$, while $27.9 \%$ had only a high school degree, and $12.1 \%$ had less than a high school degree. The majority of participants $(50.5 \%)$ had an annual income of less than $\$ 10,000$, while $27.6 \%$ earned between $\$ 10,000$ and $\$ 19,999$, and $21.9 \%$ earned more than $\$ 20,000$. In the past 30 days, the mean days of methamphetamine use was $10.43(S D=8.96)$. In the same period, the mean number of unprotected anal sex acts was 13.30 $(S D=17.09)$, with a range of $0-83$. The Negative Condom Attitudes Scale had a range from 6 to 24, with a mean score of $14.50(S D=4.47)$. BDI scores for this sample ranged from

Table 1 Hierarchical linear regression predicting unprotected sex from measure of age, income, depression, frequency of methamphetamine use, negative condom attitudes, and frequency of methamphetamine use times negative condom attitudes $(N=281)$

\begin{tabular}{|c|c|c|c|c|c|c|c|}
\hline Model & Variable & $B$ & $S E$ & Beta & $t$ & $p$ & Adjusted $R^{2}$ \\
\hline \multirow[t]{2}{*}{ Step 1} & Age & .023 & .138 & .010 & $<1$ & $\mathrm{~ns}$ & .025 \\
\hline & Income & 2.151 & .713 & .178 & 3.01 & .003 & \\
\hline \multirow[t]{3}{*}{ Step 2} & Depression score & .055 & .098 & .033 & $<1$ & ns & .150 \\
\hline & Frequency of meth use & .302 & .107 & .160 & 2.81 & .005 & \\
\hline & Condom attitudes & 1.227 & .215 & .321 & 5.70 & .000 & \\
\hline Step 3 & Meth use $\times$ Condom attitudes & .049 & .022 & .120 & 2.16 & .031 & .161 \\
\hline
\end{tabular}


0 to 62 , with a mean score of $15.32(S D=10.07)$, which falls into the mild to moderate range of depressive symptoms.

\section{Correlation Analyses}

Pearson correlation coefficients were used to examine background characteristics as correlates of negative condom attitudes, unprotected sex, and frequency of methamphetamine use. None of the background characteristics were significantly correlated with negative condom attitudes. Lower negative condom attitudes were associated with lower levels of unprotected $\operatorname{sex}(r=.35, p<.0001)$. Higher number of days of methamphetamine use was associated with higher levels of unprotected sex $(r=.18, p<.01)$. Higher depression scores were associated with a higher number of days of methamphetamine use $(r=.22, p<.0001)$ and lower income $(r=-.15, p<.01)$. Higher income was associated with more unprotected sex $(r=.17, p<.01)$. No correlation was high enough to cause concern about multicollinearity in the regression analysis.

\section{Regression Analysis}

A multiple regression analysis was conducted. The outcome of interest, total unprotected sex, was regressed on negative condom attitudes, with background characteristics, frequency of methamphetamine use, and Beck depression scores included in the regression equation. Variables that were significant in the correlation analyses were included as covariates in the regression. Age was included as an independent variable, even though it was not significantly correlated with any of the other variables, because of the strong association between younger age and sexual risk behavior in population-based studies of MSM (Xia et al., 2006). Missing data for the BDI $(n=16)$ reduced the number of participants in the regression equation to 281. Missing participants did not significantly differ from included participants on any of the demographic, predictor, or outcome variables.

Independent variables were entered in three separate steps. In the first step, age and income were entered as a block. As a block, these two variables accounted for three percent of the variance in the dependent variable. Income was the only significant variable. The direction of the beta coefficient indicated that higher income was associated with more unprotected sex.

In step two, negative condom attitudes, frequency of methamphetamine use, and Beck depression scores were entered as a block. Together, these variables accounted for an additional $14 \%$ of variance $(p<.05)$. Negative condom attitudes accounted for $10 \%$ of the variance of the outcome $(p<.001)$, while frequency of methamphetamine use accounted for $2 \%(p<.01)$. An examination of the individual test statistics indicated that methamphetamine frequency was positively associated with unprotected sex, as were negative condom attitudes. Therefore, more methamphetamine use was associated with more unprotected

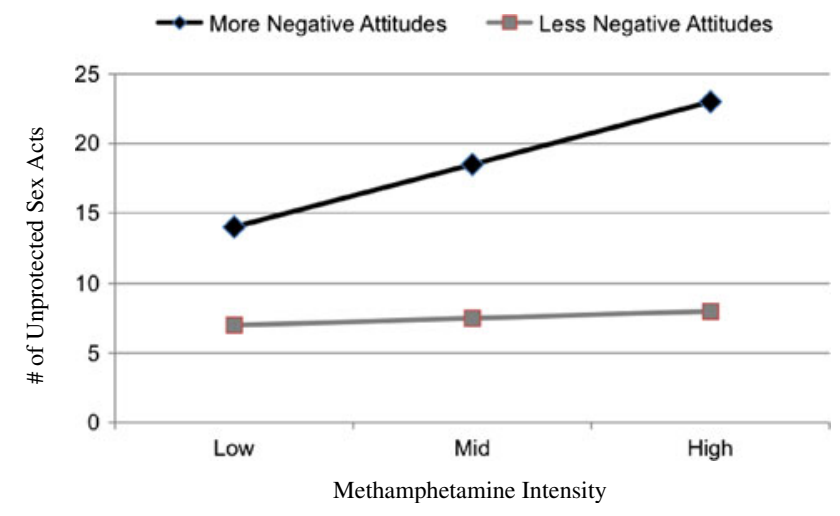

Fig. 1 Relationship between unprotected sex and methamphetamine intensity for low and high negative condom attitudes

sex, and lower scores on negative condom attitudes were associated with less unprotected sex. In the final step (three) of the regression, the interaction term (frequency of methamphetamine use times negative condom attitudes) was entered. This term was significant, suggesting a potential moderator effect.

As described above, we conducted post hoc analyses to determine the relations between methamphetamine use and unprotected sex for persons with more vs. less negative attitudes toward condoms. These analyses indicated that when individuals had more negative attitudes toward condoms, the relation between methamphetamine frequency and unprotected sex was significant $(t=3.81 ; p=.001)$. That is, greater methamphetamine use was associated with greater frequency of unprotected sex. However, among participants with less negative attitudes toward condoms, no significant association was found between methamphetamine frequency and unprotected sex $(t=1.00)$. This moderating effect is plotted in Fig. 1.

\section{Discussion}

This study investigated the relationship between methamphetamine use, attitudes about condoms, and unprotected anal sex in a sample of HIV-positive, methamphetamine-using MSM. For years now, evidence has shown that methamphetamine use is positively associated with greater levels of unprotected sex (Colfax \& Shoptaw, 2005; Halkitis et al., 2001; Semple et al., 2002). Recently, Rawstorne et al. (2007) encouraged researchers to explore other variables that are correlated with both methamphetamine use and unprotected anal sex in order to deepen our understanding of the relationship between these behaviors. So far, this study is the only one of which we are aware that has sought to identify factors that could moderate the relationship between unprotected anal sex and methamphetamine use. To evaluate the direct and independent effects of methamphetamine use and condom attitudes in relation to unprotected anal sex, we used an additive, multivariate regression model. In that model, more negative condom attitudes and higher levels of methamphetamine 
use were both independently associated with higher levels of unprotected anal sex. In addition, our data supported the hypothesis that negative condom attitudes moderate the relationship between methamphetamine use and unprotected sex. Frequency of methamphetamine use interacted with negative condom attitudes in explaining total unprotected anal sex. This interaction effect highlights the harmful role that negative condom attitudes can play in increasing the sexual risk behaviors of methamphetamine users. More specifically, this finding suggests that targeting condom attitudes in an intervention context may help to reduce the sexual risk behavior of methamphetamine-using MSM.

Despite the strong relationship between methamphetamine and risky sexual behavior that has been established in previous studies (Colfax \& Shoptaw, 2005; Halkitis et al., 2001; Semple et al., 2002), our findings indicate that methamphetamine does not affect all users in the same way. Previous research has suggested that methamphetamine users should be targeted for substance abuse interventions as a way to address their risky sexual behavior (Shoptaw et al., 2005). However, our study demonstrates that having less negative condom attitudes can play a protective role even for active users of methamphetamine. Focusing on methamphetamine-using MSM's attitudes about condoms can serve as a form of harm reduction for those who are not yet ready or willing to discontinue methamphetamine use.

We recognize that there are several limitations to this study. It is possible that other factors for which we did not account may also contribute to increased unprotected sex among those with more negative attitudes about condoms. For example, we considered neither knowledge about condoms nor about AIDS as possible contributing factors, nor did we consider other drug use besides methamphetamine. Perhaps those with better knowledge of condoms have less negative attitudes about them. Similarly, polydrug use may lead to increased unprotected sex regardless of attitudes about condoms. Drug use of sexual partners may also be an important variable. Further research should explore such additional factors that may moderate the relationship between frequency of methamphetamine use and unprotected sex. In addition, the Negative Condom Use scale used in this study has not been validated against other measures such as The Multidimensional Condom Attitudes Scale (Helweg-Larson \& Collins, 1994) or the Homosexual Attitudes toward Condom Use Scale (Ross, 1988). We encourage future studies on this topic to examine our hypothesis using other established measures of condom attitudes.

While previous research has shown a clear relationship between attitudes about condoms and engaging in unprotected sex, this relationship was not established specifically with methamphetamine-using MSM. The present study's findings support the advisability of targeting condom attitudes in safer-sex interventions for methamphetamine-using MSM, since negative attitudes towards condoms in this population are related to unprotected sex. Focusing on improving attitudes about condoms among methamphetamine-using MSM can serve as a form of harm reduction for those who are not yet ready or willing to discontinue methamphetamine use.

Acknowledgements Support for this work was provided by Grant DA021115 from the National Institute of Drug Abuse, "Behavior change and maintenance intervention for HIV+ MSM methamphetamine users" (Thomas L. Patterson, P.I.) and supplemental award DA021115-02S1.

Open Access This article is distributed under the terms of the Creative Commons Attribution Noncommercial License which permits any noncommercial use, distribution, and reproduction in any medium, provided the original author(s) and source are credited.

\section{References}

Baron, R. M., \& Kenny, D. A. (1986). The moderator-mediator variable distinction in social psychological research: Conceptual, strategic, and statistical considerations. Journal of Personality and Social Psychology, 51, 1173-1182.

Beck, A. T. (1967). Depression: Clinical, experimental and theoretical aspects. New York: Harper \& Row.

Beck, A. T. (1976). Cognitive therapy and emotional disorder. New York: Hoeber.

Benotsch, E. G., Kalichman, S., \& Cage, M. (2002). Men who have met sex partners via the internet: Prevalence, predictors and implications for HIV prevention. Archives of Sexual Behavior, 31, 177-183.

Centers for Disease Control. (2007). Methamphetamine and HIV risk among men who have sex with men [Fact Sheet]. Retrieved August 2, 2009 from http://www.effectiveinterventions.org.

Centers for Disease Control and Prevention. (2007). HIV/AIDS Fact sheet: HIV/AIDS among men who have sex with men. Retrieved November 7, 2007 from http://www.cdc.gov/hiv/topics/msm/resources/ factsheets/pdf/msm.pdf.

Colfax, G., \& Shoptaw, S. (2005). The methamphetamine epidemic: Implications for HIV prevention and treatment. Current HIV/AIDS Reports, 2, 194-199.

Crosby, G. M., Stall, R. D., Paul, J. P., \& Barrett, D. C. (1996). Condom use among gay/bisexual male substance abusers using the timeline follow-back method. Addictive Behaviors, 21, 249-257.

Grov, C., Parsons, J. T., \& Bimbi, D. S. (2008). In the shadows of a prevention campaign: Sexual risk behavior in the absence of crystal methamphetamine. AIDS Education and Prevention, 20, 42-55.

Halkitis, P. N., Parsons, J. T., \& Stirratt, M. J. (2001). A double epidemic: Crystal methamphetamine use and its relation to HIV prevention among gay men. Journal of Homosexuality, 41, 17-35.

Helweg-Larsen, M., \& Collins, B. E. (1994). The UCLA Multidimensional Condom Attitudes Scale: Documenting the complex determinants of condom use in college students. Health Psychology, 13, 224-235.

Holmbeck, G. N. (2002). Post-hoc probing of significant moderational and mediational effects in studies of pediatric populations. Journal of Pediatric Psychology, 27, 87-96.

Kraemer, H. C., \& Blasey, C. M. (2004). Centring in regression analyses: A strategy to prevent errors in statistical inference. International Journal of Methods in Psychiatric Research, 13, 141-151.

Mausbach, B. T., Semple, S. J., Strathdee, S. A., \& Patterson, T. L. (2009). Predictions of safer sex intentions and protected sex among heterosexual HIV-negative methamphetamine users: An expanded model of the theory of planned behavior. AIDS Care, 21, 17-24.

Mausbach, B. T., Semple, S. J., Strathdee, S. A., Zians, J., \& Patterson, T. L. (2007). Efficacy of a behavioral intervention for increasing safer sex behaviors in HIV-positive MSM methamphetamine users: 
Results from the EDGE study. Drug and Alcohol Dependence, 87, 249-257.

Rawstorne, P., Digiusto, E., Worth, H., \& Zablotska, I. (2007). Associations between crystal methamphetamine use and potentially unsafe sexual activity among gay men in Australia. Archives of Sexual Behavior, 36, 646-654.

Ross, M. W. (1988). Attitudes toward condoms as AIDS prophylaxis in homosexual men: Dimensions and measurement. Psychology and Health, 2, 291-299.

Semple, S. J., Patterson, T. L., \& Grant, I. (2002). Motivations associated with methamphetamine use among HIV + men who have sex with men. Journal of Substance Abuse Treatment, 22, 149-156.
Shoptaw, S., Reback, C. J., Peck, J. A., Yang, X., Rotheram-Fuller, E., Larkins, S., et al. (2005). Behavioral treatment approaches for methamphetamine dependence and HIV-related sexual risk behaviors among urban gay and bisexual men. Drug and Alcohol Dependence, $78,125-134$.

Xia, Q., Osmond, D. H., Tholandi, M., Pollack, L. M., Zhou, W., Ruiz, J. D., et al. (2006). HIV prevalence and sexual risk behaviors among men who have sex with men: Results from a statewide populationbased survey in California. Journal of Acquired Immune Deficiency Syndrome, 41, 238-245. 